\title{
Efficiency of Price Discovery in Thinly Traded Stocks: Evidence from Dual Listings in Tel Aviv and the OTC*
}

\author{
Shmuel Hauser \\ Ben Gurion University of the Negeve and Israel Securities Authority, Israel \\ Azriel Levy \\ Bank of Israel and the Hebrew University, Israel
}

The increasing popularity of non-dealer security markets that offer automated, computer-based, continuous trading reflects the conventional wisdom that such markets are more efficient for all issues, large and small. This article uses a recent testing methodology to estimate the relative efficiency of discrete versus continuous trading regimes in the price discovery of thinly traded stocks. The empirical tests use over 9,000 transactions of dually listed stocks traded discretely on the Tel Aviv Stock Stock Exchange and continuously in the Over-The-Counter market in the U.S. It is shown that stock prices over-react to the arrival of new information and noise trading in both markets, but more so under continuous trading in the OTC market. It is also shown that continuous trading generates larger pricing errors and related return volatility. These findings suggest that a switch of thinly traded securities from discrete to continuous trading may lower the efficiency of price discovery and raise return volatility (JEL G14, G15).

Keywords: continuous trading, discrete trading, pricing efficiency, Tel Aviv Stock Exchange, trading mechanism.

\section{Introduction}

This article compares the efficiency of price discovery under discrete and continuous trading for small stocks characterized by a low trading

\footnotetext{
${ }^{*}$ We are indebted to Yakov Amihud, Yoav Friedman, Shmuel Kandel, Beni Lauterbach, and Haim Levy for useful comments, and to Peter Theodossiou and Uzi Yaari for their invaluable help in refining our estimation model and writing the final draft. This research was supported by the Krueger Fund.
}

(Multinational Finance Journal, 1998, vol. 2, no. 2, pp. 133-149)

(CMultinational Finance Society, a nonprofit corporation. All rights reserved. DOI: $10.17578 / 2-2-3$ 
volume. It follows in the steps of a growing number of studies showing that market structure has important consequences for the behavior of stock prices. ${ }^{1}$ The focus on small issues is motivated by the recent trend of establishing computerized continuous trading in stock markets worldwide, including emerging markets which are dominated by small issues and low-volume trade. Most articles investigate market microstructure effects on the pricing of securities by assessing market liquidity through the bid-ask spread, liquidity ratios, or return-variance ratios. $^{2,3,4}$ Grossman and Miller (1988) criticize the use of the bid-ask spread and liquidity ratios as measures of market liquidity. They argue that the bid-ask spread overstates the transaction costs of a market maker, and liquidity ratios fail to distinguish between transitory price changes and permanent changes. According to Hasbrouck (1993), the main drawback of variance ratios is their sensitivity to the horizon used in their estimation. ${ }^{5}$ Instead, he proposes a decomposition of the return variance into two components: one due to efficient pricing and the other due to illiquidity costs. ${ }^{6}$ In his model, the quality of a trading mechanism is measured by the ability to facilitate efficient price discovery and enhance market liquidity. If a stock's pricing error is defined as the difference between observed transaction price and unobserved intrinsic value, smaller pricing errors reflect a better trading mechanism.

This article extends previous evidence on the effects of the trading mechanism on liquidity by testing the hypothesis advanced by Hauser, Levy, and Yaari (1999) that the efficiency of price discovery of thinly traded securities may be greater under discrete trading than under a

1. For example, Garman (1976), Mendelson (1982), Amihud and Mendelson (1987), Grossman and Miller (1988), and Domwitz and Wang (1994).

2. See Roll (1984).

3. See Cooper, Groth, and Avera (1985), Hasbrouck and Schwartz (1988), and Tanner and Pritchett(1992).

4. For example, George and Hwang (1995).

5. Variance ratios are defined as the return variance over a short horizon divided by the return variance over a long horizon.

6. This idea can be traced to Amihud and Mendelson(1987), Hauser, Tanchuma, and Yarri(1998), and Yaari, Garbade, and Silber (1979b) and (1987), who decompose the variance in a similar manner. 
continuous trading. According to this hypothesis, an increase in the time interval between trades produces two contradictory effects on return volatility. On the one hand, the increased flow of information per session increases the portion of return volatility caused by pricing errors; on the other hand, the increased number of traders per session decreases the average pricing error and the resulting return volatility.

The data consist of five relatively small Israeli companies whose stocks are traded discretely on the Tel-Aviv Stock Exchange (TASE) and continuously in the Over-The-Counter market (OTC) in the U.S. Using an empirical method proposed by Damodaran (1993), the effects of trading frequency on pricing efficiency are estimated by comparing across markets the portion of return volatility caused by pricing errors. ${ }^{7}$ The advantage of testing our hypothesis on dually listed stocks is that, except for differences in the trading mechanism, the absence of arbitrage opportunities ensures the same risk and return characteristics in the two markets.

The findings show that the dispersion of return caused by pricing errors is smaller under discrete trading on the TASE than under continuous trading in the OTC market. They also show that share prices over-react to the arrival of new information and noise trading in both market, but more so under continuous trading in the OTC market. These findings support the broad hypothesis that differences in price volatility across markets are at least in part attributable to different trading mechanisms. They also support the narrow hypothesis that discrete trading at some frequency can reduce the return volatility of thinly traded securities by reducing pricing errors. The underlying theory predicts that the latter effect would be economically significant only for thinly traded securities, so that discrete trading at some frequency can be optimal only for such securities. ${ }^{8}$

The remainder of the paper is organized as follows. Section II describes the main differences between the trading systems of the TASE and the OTC market. Section III discusses the methodology of testing the relative efficiency of price discovery in the two markets. The

7. See Mendelson (1982), Choen and Schwartz (1989), Forster and George (1992), and Mandhaven (1992).

8. See Hauser, Levy, and Yaari (1999) and a recent study by Amihud, Mendelson, and Lauterbach (1997). 
empirical findings are reported in section IV followed by conclusions in section $\mathrm{V}$.

\section{The Trading Mechanisms}

Three differences in the functioning of the TASE and the OTC market are related to two institutional dissimilarities: The TASE is a non-dealer market with discrete trading; the OTC is a dealer market with continuous trading. First, all orders on the TASE are accumulated and executed together; buyers and sellers in the OTC market continuously interact, directly or through dealers. Second, the TASE is an auction market; trading in the OTC is conducted through a computerized network of the National Association of Securities Dealers Automated Quote System (NASDAQ), for the most part a dealer market where investors are faced with price quotes. Based on those quotes, investors place their orders with brokers who buy and sell for their own account or execute orders with other dealers. ${ }^{9}$ Third, the TASE operates in the absence of bid-ask quotes; investors in the OTC market place their orders based on bid-ask quotes and the execution of orders usually occurs between the bid and ask prices.

In further explanation of the third difference between the two markets, it should be noted that during the sampling period there were two different trading methods on the TASE. ${ }^{10}$ The first method is a computerized call market for the least liquid stocks. It serves as a fully automated batch market designed to mimic the preceding auction session in which participants on the trading floor react to the difference between aggregated orders to buy (demand) and sell (supply) subject to price limits. The second method, designed for the 100 most liquid stocks, is based on bilateral semi-continuous trading. The trading day begins with an opening session of a call market similar to the computerized call system. This session, designed for the execution of small orders, informs traders about the market trend. ${ }^{11}$ The opening

9. See Blume and Siegel (1992)

10. See Bronfeld (1994).

11. Notice that the opening price is set only towards the end of the first round in the main session. At the time trading in the main session begins, the price of the opening session is not 
session is followed by the main auction session consisting of a few rounds in which the 100 stocks are traded in three separate groups, in separate rooms. In each round, trading in each room begins with the auctioneer's announcement of the stock traded first, followed by announcements by interested buyers and sellers of the opening bid and ask prices. Price gaps are closed by negotiation which is open to other exchange members. A price agreement results in transactions followed by an announcement of the next stock to be traded - a process which is repeated until all stocks have been traded. The first round is followed by the auctioneer's announcement of the second round, etc. Trading, which ends at 4:00 PM, averaged six rounds per stock per day during the sampling period.

\section{Methodology}

The empirical model developed below is designed to compare the efficiency of price discovery under the two trading mechanisms. It is based on a theoretical price adjustment model of Amihud and Mendelson (1987). It is followed by a description of related empirical model proposed by Damodaran (1993).

\section{A. Noise Trading and Adjustment to New Information ${ }^{12}$}

Amihud and Mendelson (1987) specify the security price by

$$
P_{t}=\gamma V_{t}+(1-\gamma) P_{t-1}+u_{t},
$$

where $P_{t}$ is the observed price and $V_{t}$ the unobserved intrinsic value at time $t$, both expressed in natural logarithms; $\gamma$ is the price-adjustment coefficient, and $u_{t}$ is a zero-mean random error with a variance $\sigma_{u}^{2}$ Equation 1 postulates that the observed price at time $t$ is a weighted

known. The only information available at that point is about the excess of supply or demand for shares. In other words, there is no opening price on the TASE similar to that in the OTC.

12. For some of the finer points in this subsection, we are indebted to the managing editor Peter Theodossiou. 
average of the intrinsic value at that time and the observed price at $t-1$. The coefficient $\gamma$ measures the speed of price adjustment towards the intrinsic value. The value $\gamma=1$ implies instantaneous (full) adjustment, so that

$$
P_{t}=V_{t}+u_{t}
$$

The value $\gamma=0$ implies no price adjustment toward the changing intrinsic value, so that

$$
P_{t}=P_{t-1}+u_{t},
$$

where the price logarithm follows a pure random walk process. The intrinsic value is specified as a random walk process with a drift

$$
V_{t}=m+V_{t-1}+e_{t}
$$

where the drift, $m$, is measured as continuously-compounded periodic return, and $e_{t}$ is a zero-mean random error with a variance $\sigma_{e}^{2}$. Note that $m=E\left(V_{t}-V_{t-1}\right)$ represents the expected growth rate of $V_{t}$. It follows from (1) and (2) that

$$
V_{t}-P_{t}=(1-\gamma) m+(1-\gamma)\left(V_{t-1}-P_{t-1}\right)+(1-\gamma) e_{t}-u_{t}
$$

and after recursive substitution

$$
\begin{aligned}
V_{t}-P_{t}= & (1-\gamma) m \sum_{s=1}^{t}(1-\gamma)^{s-1}+(1-\gamma)^{t}\left(V_{0}-P_{0}\right) \\
& +\sum_{s=1}^{t}(1-\gamma)^{s-1}\left((1-\gamma) e_{t-s+1}-u_{t}\right) \\
= & (1-\gamma) m\left(\frac{1-(1-\gamma)^{t}}{\gamma}\right)+(1-\gamma)^{t}\left(V_{0}-P_{0}\right)
\end{aligned}
$$




$$
+\sum_{s=1}^{t}(1-\gamma)^{s-1}\left((1-\gamma) e_{t-s+1}-u_{t}\right)
$$

The assumptions $t \rightarrow \infty$ and $0<\gamma<2$ imply $\lim _{t \rightarrow \infty}(1-\gamma)^{t}=0$, allowing simplification of the last equation to

$$
V_{t}-P_{t}=(1-\gamma) m+\sum_{s=1}^{t}(1-\gamma)^{s-1}\left((1-\gamma) e_{t-s+1}-u_{t+s-1}\right)
$$

With the additional assumption $\lim _{t \rightarrow \infty}(1-\gamma)^{t}=0$, the expectation and variance of (4) are

$$
E\left(V_{t}-P_{t}\right)=\frac{1-\gamma}{\gamma} m
$$

and

$$
\begin{gathered}
\operatorname{var}\left(V_{t}-P_{t}\right)=\sum_{s=1}^{t}(1-\gamma)^{2(s-1)} \operatorname{var}\left((1-\gamma) e_{t-s+1}-u_{t-s+1}\right) \\
=\frac{\left(1-(1-\gamma)^{2 t}\right)}{1-(1-\gamma)^{2}}\left((1-\gamma)^{2} \sigma_{e}^{2}+\sigma_{u}^{2}\right) \\
=\frac{(1-\gamma)^{2}}{1-(1-\gamma)^{2}} \sigma_{e}^{2}+\frac{1}{1-(1-\gamma)^{2}} \sigma_{u}^{2} .
\end{gathered}
$$

Equation 5 shows that under a slow market adjustment to new information, indicated by a coefficient in the interval $0<\gamma<1$, the security price will systematically understate the intrinsic value, $P_{t}<V_{t}$. Instantanuous adjustment, indicated by $\gamma=1$, will cause $P_{t}=V_{t}$. Market overreaction, indicated by $1<\gamma<2$, will lead to systematic overpricing, $P_{t}>V_{t}$.

Based on equations 1 and 2 , the rate of return, $R_{t}$, is defined by

$$
R_{t} \equiv P_{t}-P_{t-1}=\gamma\left(V_{t-1}-P_{t-1}\right)+u_{t}
$$




$$
=\gamma\left(V_{t-1}-P_{t-1}\right)+\gamma m+\gamma e_{t}+u_{t}
$$

Substitution of (4) in the right-hand side of the last expression yields

$$
\begin{gathered}
R_{t}=(1-\gamma) m+\gamma \sum_{s=1}^{t}\left[(1-\gamma)^{s-1}\left((1-\gamma) e_{t-s+1}-u_{t-s+1}\right)\right]+\gamma m+\gamma e_{t}+u_{t} \\
=\gamma \sum_{s=1}^{t}\left[(1-\gamma)^{s-1}\left((1-\gamma) e_{t-s+1}-u_{t-s+1}\right)\right]+\gamma e_{t}+u_{t} \\
+m+\gamma \sum_{s=1}^{t}(1-\gamma)^{s}\left(e_{t}-u_{t-s+1}\right)+u_{t} .
\end{gathered}
$$

Based on (7), the return mean and variance are

$$
E\left(R_{t}\right)=m
$$

and

$$
\begin{gathered}
\operatorname{var}\left(R_{t}\right) \equiv \sigma_{r}^{2}=\frac{\gamma^{2}(1-\gamma)^{2}}{1-(1-\gamma)^{2}} \sigma_{e}^{2}+\frac{\gamma^{2}}{1-(1-\gamma)^{2}} \sigma_{u}^{2}+\gamma^{2} \sigma_{e}^{2}+\sigma_{u}^{2} \\
=\frac{\gamma^{2}}{1-(1-\gamma)^{2}} \sigma_{e}^{2}+\frac{2 \gamma}{1-(1-\gamma)^{2}} \sigma_{u}^{2} \\
=\frac{\gamma}{2-\gamma} \sigma_{e}^{2}+\frac{2}{2-\gamma} \sigma_{u}^{2} .
\end{gathered}
$$

Equations 7, 8, and 9 provide the basis for comparing the pricing efficiency of each of the five thinly traded stocks under discrete and continuous trading. Damodaran's empirical model described below is used to estimate the parameters of (9); $\gamma, \sigma_{e}^{2}$, and $\sigma_{u}^{2}$.

\section{B. Damodaran's Model}

Damodaran (1993) provides a method for estimating the price adjustment coefficient $\gamma$ in the Amihud-Mendelson model. This parameter, which quantifies the extent of adjustment of transaction 
prices towards the security's intrinsic value, is used in estimating the portion of return variance caused by price adjustment. This portion of the variance is attributed to information-uncorrelated pricing errors caused by noise trading and illiquidity. This model decomposes the variance of $R_{t}$ according to

$$
\sigma_{r}^{2}=\sigma_{e}^{2}+2 \sigma_{u}^{2}+\left(\frac{\gamma}{2-\gamma}-1\right) \sigma_{e}^{2}+\left(\frac{2}{2-\gamma}-2\right) \sigma_{u}^{2},
$$

where the last two terms represent the return volatility caused by price adjustment. When $\gamma \neq 1$, clearly $\sigma_{r}^{2}$ is a biased estimator of the dollar return variance, $\sigma_{e}^{2}$. Full price adjustment is represented by $\gamma=1$, a case in which $\sigma_{r}^{2}=\sigma_{e}^{2}+2 \sigma_{u}^{2}$. Following equations 7-10, Damodaran derives a measure of $\gamma$ based on three assumptions: ${ }^{13}$ (1) $V_{t}$ is i.i.d and follows a random walk; (2) the noise terms and intrinsic value processes are independent; and (3) the price-adjustment coefficient approaches unity as the trading interval is extended. Under these assumptions, the variance of returns over a trading interval $j$ is

$$
\operatorname{var}\left(R_{j, t}\right)=\left[\frac{\gamma_{j}}{2-\gamma_{j}} j \sigma_{e}^{2}+\frac{2}{2-\gamma_{j}} \sigma_{u}^{2}\right]
$$

where $\gamma_{j}$ is the price adjustment coefficient for $j$-interval returns. Assuming $j=1,2, \ldots, k$, where $k$ is a sufficient trading interval allowing $\gamma=1$, Damodaran shows that

$$
\operatorname{var}\left(R_{j, t}\right)-\frac{\operatorname{var}\left(R_{k, t}\right)}{k}=\sigma_{e}^{2}\left[\frac{\gamma_{j}}{2-\gamma_{j}}\right]+2 \sigma_{u}^{2}\left[\frac{1}{2-\gamma_{j}}-\frac{1}{k}\right],
$$

where the noise term variance is $\sigma_{u}^{2}=-\operatorname{cov}\left(R_{k, t}, R_{k, t-1}\right)$ and the intrinsic value variance is $\sigma_{e}^{2}=\left[\operatorname{var}\left(R_{k, t}\right)+2 \operatorname{cov}\left(R_{k, t}, R_{k, t-1}\right)\right] / k$. Substitution of (11), $\sigma_{e}^{2}$ and $\sigma_{u}^{2}$ into (12) yields Damodaran's estimated

13. See discussion in Damodaran (1993), p. 389. 
$\gamma_{j}$ for any trading interval $j^{14}$

$$
\gamma_{j}=\frac{2 \operatorname{var}\left(r_{j, t}\right) / j+2 \operatorname{cov}\left(r_{k}, r_{k, t-1}\right) / j}{\operatorname{var}\left(r_{j, t}\right) / j+\operatorname{var}\left(r_{k, t}\right) / k+2 \operatorname{cov}\left(r_{k, t}, r_{k, t-1}\right) / k} .
$$

In estimating $\gamma_{j}$ from (13), we follow Damodaran by assuming $k=15$ days. ${ }^{15}$

\section{Test Results}

\section{A. Data}

Of the five dually listed stocks examined in this paper, four (Teva, Elbit, Elron, and Aryt) were traded on the TASE in the semi-continuous system, and one (Robotec) was traded once a day. Strictly speaking, both trading methods are discrete. Although during the sampling period there were close to sixty Israeli companies listed in the U.S., only seven of them were dually listed. Incomplete data for two of the companies reduce the sample to five stocks. The sampling period starts in July 1988 to avoid the effect of the October 1987 market crash in the U.S. (see Malliaris and Urratia (1993)), and ends in September 1993, six months before the Israeli market crash. In February 1994 stock prices on the TASE dropped by an average of 40 percent. The decision not to extend the sample beyond 1993 was further prompted by a 1994 policy change of the Bank of Israel that increased the exchange rate volatility by relaxing the foreign exchange control (more on this below). Any damage caused by ending the sampling period in September 1993 is likely to be small in view of our finding that different sub-periods between July 1988 and September 1993 generate similar results. The decision not to extend the sample beyond 1993 was further influenced by data problems starting in 1994 for two of the companies. An

14. This formula is Brisley and Theobald's (1996) correction to the one suggested by Damodaran (1993).

15. For a detailed discussion and empirical results concerning the choice of $\tau$, see Damodaran (1993). 
ownership change in Aryt caused a substantial increase in trading volume, and problems in compiling Robotec's stock prices damaged the quality of its data. Our data consist of over 9,000 daily closing share prices and trading volume for the five stocks in both markets and daily closing figures of the S\&P 500 and the TASE general stock index. Rates of return (log returns) of the five stocks were adjusted for dividends and splits.

Three data-related issues deserve further consideration. The first issue concerns the shekel denomination of stock prices on the TASE. Those prices were converted to U.S. dollars at the relevant exchange rate so that dollar rates of return on the TASE include rates of return in Israeli currency plus the change in the exchange rate. The potential difficulties created by relying on a "representative" exchange rate concern its synchronization with closing stock prices and its relevance as a market price. These potential difficulties do not appear to interfere with our results because the same rate was used by all Israeli banks and in most foreign exchange transactions throughout the day. ${ }^{16}$ Moreover, most investors in the stocks studied were Israelis who could legally buy and sell foreign currency only in Israeli banks and therefore only at the same rate. The insignificance of these factors is further suggested by evidence that the correlation coefficient between stock returns and percentage changes of the exchange rate was close to zero, and the daily volatility of the exchange rate was less than $3 \%$ of the daily volatility of share prices. To further examine the effect of this issue on our results, we recalculated the results using alternatively the spot exchange rate of the previous and following days to find only negligible effect on the results.

The second issue concerns the time difference between the two markets, since trading in New York begins approximately when trading in Tel Aviv ends. The risk and return parameters are not affected by the time difference since they are estimated separately in each market. This allows us to circumvent the problem raised by Kahya (1997), who argues that contemporaneous correlation measures must be adjusted for

16. This practice was recently changed. During the sampling period the exchange rates was, to a large extent, determined by the Bank of Israel which daily sold and bought foreign reserves equal to the market excess demand or supply. The representative exchange rate set at noon was the one that cleared the market between the commercial banks and the central bank. 
TABLE 1. Derscriptive Statistics of the Five Dually Listed Stocks

\begin{tabular}{|c|c|c|c|c|c|c|c|c|c|}
\hline \multirow[b]{2}{*}{ Firm } & \multirow[b]{2}{*}{ Market } & \multirow[b]{2}{*}{$\begin{array}{l}\text { Sample } \\
\text { Period }\end{array}$} & \multirow{2}{*}{$\begin{array}{l}\text { Daily Volume } \\
\text { of Trade } \\
\text { Million \$ }\end{array}$} & \multicolumn{2}{|c|}{ Average of } & \multicolumn{4}{|c|}{ Log Returns \% } \\
\hline & & & & $\begin{array}{l}\text { Share } \\
\text { Price \$ }\end{array}$ & $\begin{array}{l}\text { Log } \\
\text { Spread \% }\end{array}$ & Mean & $\begin{array}{l}\text { Standard } \\
\text { Deviation }\end{array}$ & Skewness & Kurtosis \\
\hline \multirow[t]{3}{*}{ Teva } & OTC & 7/88-9/93 & 2.555 & 12.43 & 2.35 & .157 & 3.080 & .05 & 2.52 \\
\hline & TASE & & 1.079 & & & .172 & 2.350 & -.04 & 1. 42 \\
\hline & & & & & (.38) & (100.9) & & & \\
\hline \multirow[t]{3}{*}{ Elbit } & OTC & 7/88-9/93 & .360 & 21.52 & 2.26 & .175 & 2.540 & .25 & 2.52 \\
\hline & TASE & & 1.088 & & & .182 & 2.290 & -.13 & 2. 72 \\
\hline & & & & & $(.55)$ & (19.3) & & & \\
\hline \multirow[t]{3}{*}{ Elron } & OTC & 7/88-9/93 & .193 & 11.27 & 3.29 & .139 & 3.452 & .23 & 2.13 \\
\hline & TASE & & .461 & & & .155 & 2.580 & -1.02 & 10.01 \\
\hline & & & & & (.03) & (128.9) & & & \\
\hline \multirow[t]{3}{*}{ Robotec } & OTC & $8 / 92-11 / 93$ & .061 & 2.68 & 7.16 & .001 & 3.779 & .03 & .57 \\
\hline & TASE & & .042 & & & .002 & 2.480 & -.23 & 5.90 \\
\hline & & & & & (.10) & $(27.7)$ & & & \\
\hline \multirow[t]{3}{*}{ Aryt } & OTC & 8/92-11/93 & .023 & 2.61 & 9.18 & .213 & 4.369 & .26 & 1.20 \\
\hline & TASE & & .212 & & & .208 & 3.150 & -.17 & .86 \\
\hline & & & & & $(.01)$ & (107.7) & & & \\
\hline NIS/\$ & & 7/88-11/93 & & 2.302 & & .00037 & .00467 & 3.312 & 40.196 \\
\hline
\end{tabular}

Note: The log-spread represents the average percentage difference between the bid and ask quotes based on end-of-the-month figures reported by Bloomberg. All figures are calculated over the entire sampling period. For all five stocks, the null hypothesis of equal mean returns across markets cannot be rejected using a two-sample $t$-test (numbers in parenthesis are $t$-values). The standard deviation of returns indicates rejection of the null hypothesis of equal volatility across markets using Pitman's test for dependent samples (numbers in parenthesis are F-values). NIS/\$ is the representative New Israeli Shekel against the U.S. dollar. 
non-overlapping trading hours of stock markets. This issue is further examined below.

The third issue concerns the use of closing prices rather than intraday transaction prices. Garbade and Silber (1979a) and Hauser, Levy, and Yaari (1999) demonstrate that disturbances do not accumulate over the observation period. This finding allows us to gauge the pricing error variance of consecutive transactions from closing prices. Note that our empirical analysis is limited to close-to-close returns since the data do not allow us to break the analysis into open and close periods. Separating the analysis into open and close returns has the advantage that they do not overlap in time as do close-to-close returns (see Amihud and Mendelson (1987)). However, as pointed out above, open share prices did not exist on the TASE.

\section{B. Desriptive Statistics: Volume, Spread, Mean Return, and Volatility}

This section provides descriptive statistics of the data. Figures displayed in table 1 show significant differences in the volume of trade between the two markets and among the securities in each. This is reflected in the large bid-ask spread that characterizes our thinly traded stocks. Except for Teva and Robotec, the average daily trading volume is higher in the TASE than in the OTC. However, even in these two stocks, the trading volume per transaction is higher on the TASE due to a smaller number of transactions. This point is further discussed below.

In addition, we computed the average rate of return and standard deviation. As expected, the results displayed in table 1 indicate that the annual mean rates of return in the two markets are not significantly different. Yet, the standard deviations are significantly different. Having discarded the possibility that significant differences in return volatility were caused by exchange rate volatility (see Section 4.A), the article proceeds to examine the impact of differences in the trading methods.

\section{Damodaran's Model}

Information-uncorrelated pricing errors are those "likely to result from price discreteness, transient liquidity effects, inventory control effects, and noise trading" (Hasbrouck [1993], p.197). Table 2 reports estimates of the speed of price adjustment to arriving new information and its 
TABLE 2. Information-Uncorrelated Pricing Errors: Damodaran's Method

\begin{tabular}{|c|c|c|c|}
\hline Firm & Market & $\begin{array}{l}\text { Price Adjustment } \\
\text { Coefficient, } \gamma_{1}\end{array}$ & $\begin{array}{l}\text { Price Adjustment Effect } \\
\text { on Return Volatility }\end{array}$ \\
\hline \multirow[t]{2}{*}{ Teva } & OTC & 1.204 & .654 \\
\hline & TASE & 1.109 & .238 \\
\hline \multirow[t]{2}{*}{ Elbit } & OTC & 1.069 & .282 \\
\hline & TASE & 1.007 & .235 \\
\hline \multirow[t]{2}{*}{ Elron } & OTC & 1.205 & .551 \\
\hline & TASE & 1.055 & .525 \\
\hline \multirow[t]{2}{*}{ Robotec } & OTC & 1.427 & 1.002 \\
\hline & TASE & 1.070 & .263 \\
\hline \multirow[t]{2}{*}{ Aryt } & OTC & 1.436 & .778 \\
\hline & TASE & 1.122 & .223 \\
\hline \multicolumn{4}{|c|}{ Kruskal Wallis } \\
\hline \multicolumn{2}{|l|}{ Statistic } & 3.94 & 5.77 \\
\hline \multicolumn{2}{|l|}{ P-value } & .047 & .016 \\
\hline
\end{tabular}

Note: The relative quality of a trading mechanism is tested by comparing price adjustment to new information in the two markets. The methodology relies on the AmihudMendelson model for the difference between a security's intrinsic value and observed price, where $\gamma$ is the price adjustment coefficient $(0<\gamma<2)$ and $u_{t}$ is a noise term. The value $\gamma=1$ indicates full price adjustment to new information, and $\gamma$ price over-reaction to new information. Parameter $\gamma$ is estimated based on Damodaran's method decomposing the variance of $r_{t}$ into four components:

$$
\sigma_{r}^{2}=\sigma_{e}^{2}+2 \sigma_{u}^{2}+\left(\frac{\gamma}{2-\gamma}-1\right) \sigma_{e}^{2}+\left(\frac{2}{2-\gamma}-2\right) \sigma_{u}^{2},
$$

where the last two represent the price adjustment effect on return volatility. If the trading time interval, $\kappa$, is sufficient to allow $\gamma=1$, the price adjustment coefficient $\gamma_{j}$ for any interval $j$ is

$$
\gamma_{j}=\frac{2 \operatorname{var}\left(r_{j, t}\right) / j+2 \operatorname{cov}\left(r_{k}, r_{k, t-1}\right) / j}{\operatorname{var}\left(r_{j, t}\right) / j+\operatorname{var}\left(r_{k, t}\right) / k+2 \operatorname{cov}\left(r_{k, t}, r_{k, t-1}\right) / k},
$$

where $j=1,2, \ldots, \tau$, and $r_{j, t}$ and $r_{k, t}$ are the returns for trading interval $j$ and $\kappa$, respectively. Following Damodaran, we assume $k=15$ days in estimating $\gamma_{j}$. Coefficient $\gamma_{1}$ is the one-day speed of adjustment. Kruskal-Wallis statistics are based on the Kruskal-Wallis non-parametric test for cross-sectional comparison of medians.

effect on return volatility based on Amihud and Mendelson (1987) and Damodaran's (1993) model for estimating the speed of adjustment. In all cases, prices adjust faster on the TASE than in the OTC market, consistent with the hypothesis that discrete trading on the TASE leads 
to greater pricing efficiency. ${ }^{17}$ Above-one coefficients of price adjustment averaging 1.268 in the OTC market and 1.073 on the TASE suggest that in both markets stock prices tend to over-react to arriving new information, but more so under continuous trading. Like Damodaran, we recognize that this estimation procedure does not include significance tests (see Damodaran (1993) p. 393). Therefore, following Damodaran, we added a non-parametric test (Kruskal Wallis) for cross-sectional comparison of medians. The results indicate, again, that stock prices tend to over-react to arriving new information, and more so under continuous trading at the $4.7 \%$ significance level. Consistently, the return volatility attributed to price adjustment - the sum of the last two terms in equation 10 - is greater in the OTC market for all five securities (see column 4 in table 2) at the $1.6 \%$ significnace level. These results unambiguously confirm the hypothesis that thinly traded securities may be more efficiently priced under discrete trading than under continuous trading.

\section{Summary and Conclusions}

This paper extends previous evidence on the effects of the trading mechanism on market liquidity, focusing on the efficiency of price discovery of small issues under discrete versus continuous trading. The extensive study of a small number of thinly-traded stocks dually listed on the TASE and the OTC shows that those stocks are more efficiently traded at discrete time intervals on the TASE than continuously in the OTC market. A comparison of the two markets shows that, for each of the stocks studied, the portion of return volatility attributed to pricing errors is significantly greater under continuous trading in the OTC market. It also shows that stock prices overreact to new information and noise trading in both markets, but more so under continuous trading in the OTC market. These findings support the broad hypothesis that differences in return volatility across markets are, at least in part, attributable to the use of different trading mechanisms. They also support the narrow hypothesis that discrete trading at some frequency can reduce the return volatility of thinly traded securities.

17. An alternative explanation for the faster price adjustment on the TASE is the dominant role played by the home market where much of the information is released. See Chowdhry and Nanda (1991) and Hauser, Levy, and Yaari (1999). 


\section{References}

Amihud, Y. and Mendelson, H. 1987. Trading mechanisms and stock returns: an empirical investigation. Journal of Finance 42: 533-553.

Amihud, Y. and Mendelson, H. 1991. Volatility, efficiency, and trading: evidence from the Japanese stock market. Journal of Finance 46: 17651789.

Amihud, Y.; Mendelson, H.; and Murgia, M. 1990. Stock market microstructure and return volatility: Evidence from Italy. Journal of Banking and Finance 14: 423-440.

Amihud, Y.; Mendelson, H.; and Lauterbach, B. 1997. Market microstructure and securities values: Evidence from the Tel Aviv Stock Exchange. Journal of Financial Economics 45: 365-395.

Blume, M. E. and Siegel, J. J. 1992. The theory of security pricing and market structure. Financial Markets, Institutions \& Instruments, New York University Salomon Center.

Brisley, N. and Theobald, M. 1996. A simple measure of price adjustment coefficients: A correction. Journal of Finance 51: 381-382.

Bronfeld, S. June 1994. Trading systems on the Tel Aviv Stock Exchange. The Tel Aviv Stock Exchange.

Cohen, K. J. and Schwartz, R. A 1989. An electronic call market: Its design and desirability. The Challenge of Information Technology for the Securities Market: Liquidity, Volatility, and Global Trading, Homewood, IL: Dow Jones-Irwin.

Chwodhry, B. and Nanda, V. 1991. Multimarket trading and market liquidity. Review of Financial Studies 4: 483-512.

Cohen, K. J.; Maier, S. F.; and Schwartz, R.A. 1986. The Microstructure of Securities Markets, Englewood Cliffs, NJ: Prentice Hall.

Cooper, K.; Groth, J.; and Avera, W. 1985. Liquidity, exchange listing, and common stock performance. Journal of Economics and Business 37: 21-33.

Damodaran, A. 1993. A simple measure of price adjustment coefficients. Journal of Finance 48: 387-400.

Domowitz, I. and Wang. J. 1994. Auctions as algorithms: Computerized trade execution and price discovery. Journal of Economic Dynamics and Control: 29-60.

Forster, M. M. and George, T. J. 1992. Volatility, trading mechanisms, and international cross-listing. Working Paper. Ohio State University.

Garbade, K. D. and Silber, W. L. 1979a. Dominant and satellite markets: A study of dually-traded securities. Review of Economics and Statistics 61: 455-460.

Garbade, K. D. and Silber, W. L. 1979b. Structural organization of secondary markets: Clearing frequency, dealer activity and liquidity risk. Journal of Finance 34: 577-593.

George, T. J. and Hwang, C. H. 1995. Transitory price changes and price-limit 
rules: Evidence from the Tokyo Stock Exchange. Journal of Financial and Quantitative Analysis 30: 313-327.

Grossman, S. J. and Miller, M. H. 1988. Liquidity and market structure. Journal of Finance 43: 617-633.

Hasbrouck, J. 1993. Assessing the quality of a security market: A new approach to transaction-cost measurement. Review of Financial Studies 6: 191-212.

Hasbrouck, J. and Schwartz, R. A. 1988. An assessment of stock exchange and over-the- counter markets. Journal of Portfolio Management 14: 10-16.

Hauser, S.; Levy, A; and Yaari, U. 1999 Discrete vs. continuous trading: Designing thin markets for minimum price volatility. Forthcoming, European Journal of Finance.

Hauser, S.; Tanchuma, Y; and Yaari, U. 1998. International transfer of pricing information between dually listed stocks. Journal of Financial Research 21: 139-157.

Kahya, E. 1997. Correlation of returns in non-contemporaneous markets. Multinational Finance Journal 2: 123-134.

Madhavan, A. 1992. Trading mechanisms in securities markets. Journal of Finance 47: 607-641.

Malliaris, A.G. and J.L. Urrutia. 1992. The international crash of October 1987: causality tests. Journal of Financial and Quantitative Analysis 27: 353-364.

Mendelson, H. 1982. Market behavior in a clearinghouse. Econometrica 50: 1505-1524.

Roll, R. 1984. A simple model of the implicit bid-ask spread in an efficient market. Journal of Finance 39: 1127-1139.

Tanner, J. E. and Pritchett. B. 1992. The pricing of market maker services under siege: NASDAQ vs. NYSE on black monday. The NASDAQ Handbook, Chicago, IL: Probus. 